\title{
The Impact of Third Party Payment on Commercial Banks
}

\author{
Li-Hong YANG ${ }^{1, a}$, Xiao-Tian LIANG $^{1, b, *}$ \\ ${ }^{1}$ School of Management, Xi'an University of Science and Technology, Xi'an, Shaanxi, China \\ a1506649007@qq.com , b15091677566@163.com
}

Key words: Commercial bank, Third party payment, Impact, Countermeasure.

\begin{abstract}
With the rapid development of Internet finance, E-commerce has gradually become the mainstay of commodity trading process under the development of Internet technology, and the third-party payment platform conforms to the opportunity of the development of e-commerce era. Third-party payment institutions have established a powerful transaction guarantee platform between consumers and merchants. The third-party payment platform not only promotes the economic development of our country, but also promotes the vigorous development of e-commerce field. In the case of third-party payment institutions and banks depending on each other, due to the third party payment platform of China's laws and regulations and regulatory measures are not perfect. The risk of third-party payment platform is easily transferred to the banking system. In summary, it is particularly important to study the impact of third-party payment institutions on banks. It also provides corresponding countermeasures for banks to deal with the impact of third-party payment institutions.
\end{abstract}

\section{Comparison between Third-Party Payment and Traditional Payment in Financial System}

Third-party payment provides a trading platform that interfaces with the bank's payment and settlement system, and contracts with the major banks, to a certain extent, plays a role similar to the central bank's payment and clearing, and also assumes the function of credit guarantee.

The third party pays the second settlement, compared with the more programmed. The traditional payment mode only needs to be established between the commercial bank and the customer. Commercial banks, with the permission of the central bank, can transfer money directly from one account to another. In settlement, only funds are settled between commercial banks and customers.

The existence of personal financial accounts. Traditional financial institutions and qualified Internet companies can provide individual financial accounts, traditional financial institutions in the individual financial account monopoly pattern has been broken, such as Alipay account. QQ accounts. This makes personal financial accounts to achieve multi-directional development. In the rapid development of e-commerce environment, holding personal accounts, through computers or mobile terminals to operate.

The attributes of financial commodities. The rapid development of electronic commerce in the general environment. It makes third-party payment and mobile payment have different financial commodity attributes from other payment modes. Financial commodity attributes increase the difficulty of currency control for third-party payment and mobile payment. It also makes it more attractive. Payment money itself is a financial commodity or can be automatically converted between means of payment and financial goods.

Payment of Transaction Cost, transaction cost of financial commodity and currency conversion difference in transaction costs in the era of electronic money is lower than the conversion of precious metal era monetary and financial cost of goods. At the same time, in the era of electronic money, payment mobility and mobile payment mobility characteristics, is reduced. The transaction cost of financial commodity and currency conversion is necessary.

The flow is convenient .As a new star of payment intermediary, third-party payment to users 
enjoys a more convenient experience than traditional banks. Through third-party payment to the transaction between the parties to the transaction platform. In cooperation with third-party payment agencies, the financial services of a number of banks simplify the process and enable the receiving and payment parties to freely choose the bank's payment services.

The handling fee is lower than the traditional bank. Third-party fees to pay compared to traditional banks, its fees are lower or even free of fees, really let users feel the benefits.

Good User Experience. Compared with the third party payment institution, the traditional bank has high cost, long time, complicated payment process, and the customer's individualized needs cannot be satisfied. At present, the third party payment keeps pace with the times and simplifies the transaction procedure. Continuous innovation, to provide users with more efficient trading process, good maneuverability helps users to complete transactions on the third party trading platform.

Credit Guarantee. The people's Bank of China issues licences to third-party payment agencies and the people's Bank of China verifies their qualifications and has a strong credit guarantee, so that the interests of both parties to the transaction can be protected more effectively.

\section{The Influence of Third-Party Payment Enterprises on Commercial Banks}

\section{Reduction in Bank Intermediate Income}

The profit of bank loan business is decreasing day by day, it can be observed that intermediate business income, especially payment business income, is very important to bank profit. However, third-party payment is expanding its business field. At the same time, the characteristics of transaction guarantee are widely recognized by customers and quickly occupy a favorable position in the field of electronic commerce payment. At the same time, after the successful registration of third-party payment accounts, it is not necessary to register online banks, so that most of the payment business can be completed. The third-party payment organization carries out the business to replace the bank intermediary business intangibly.

\section{Infiltration of Traditional Business and Sales Areas}

The further expansion of third-party payment business has penetrated into the traditional industry sales areas, such as the payment of electricity and gas charges, the sale of online passenger ticket, online trading of commodities, sales of fund products. Agent insurance and other business. According to the data, the current payment through the third-party payment platform users more than half of the users of online banking, and more than the users who log on to the bank to pay. Bank online payment is directly replaced by third-party payment platform.

\section{Slow Shortcomings in User Experience Improvement are Magnified}

Domestic online banking emphasizes the development of related business based on its own, and the program design of online banking can not match the needs of users. As a result, online banking is in a disadvantaged position in the competition. Users are provided with convenient and humanized services because of the convenience and humanization of third-party payment enterprises. The requirements of users for the quality of banking services rise accordingly. In the face of the concept of security risk control into the mechanism and system of commercial banks, we often need to put risk control in the first place, sacrificing the user experience. So online banking in the user experience is a heavy task and a long way to go.

\section{Increased Risk Management Requirements}

Third party payment relies on the bank to expand the service domain unceasingly, manifests in the on-line bank, the quick payment and so on aspect. The innovation service way has facilitated the market participant, but also has brought more risks to the bank. Make criminals in the laws and regulations on the omissions can be taken advantage of. Manifested in the amount of online 
transactions, money laundering and user personal information disclosure, and so on, the bank's funds security and risk control issues have a huge threat. To the bank brings the fund security hidden danger.

\section{Case Analysis}

\section{Alipay Overview}

Alipay Network Technology Co., Ltd. in the domestic third-party payment enterprises in the dominant position. Is a subsidiary of the Alibaba Group. Alipay's corporate culture has changed now on its payment solution: providing "simple, secure" e-commerce for the Internet. In 2004, when Alipay Company was born, the products and services with "trust" as the core were implemented, so they developed in a short period of ten years. Its company has become the world's largest Internet third-party mobile payment manufacturer.

Alipay cannot be separated from excellent enterprise cultural products in a short span of ten years, mainly in the following aspects:

(1)Product performance is good: Fast, safe, simple. Funds immediately to the account, the rapid turnover of funds, Alipay cartoon funds transfer more quickly, convenient; Through Alipay real name authentication, mobile phone dynamic password and digital certificate to protect the transaction security, at the same time to provide transaction security, goods payment, to ensure the security of the two sides of the fund transaction; Simple operation procedure, on the basis of fund settlement service system and clear bill management system, simplifies the flow of traditional business.

(2)High Prevalence: The powerful brand culture of Alipay treasure is infiltrated into every corner of the city without the need of money to pay for the daily life of all aspects of payment , and at the same time reap the benefits in the process of using the Alipay treasure, and the transaction can be completed immediately by sweeping the code, and it is no exaggeration to say that it has become a way of life of people .

(3) Users are Highly Operational: On the one hand, users can easily operate online to meet the payment needs of users at all levels, but also can off-line mobile payment, recharging online stores and other ways to pay.

(4) Low Threshold for Merchants. The threshold limit of commercial households is lower, which provides low threshold products to new businesses, according to the actual transaction volume of $3 \%$ charges, more than 100 million Alipay users, to provide huge business opportunities.

\section{Payment Operating Model}

Alipay is in fact a virtual account, through the virtual account of the relevant bank account funds transfer, is through Alipay users and related bank accounts to bind, to carry out the flow of funds between accounts. But must rely on the commercial bank foundation carries on the service operation, is a kind of medium which the electronic commerce currency carries on the activity.

\section{The Impact of Alipay on Commercial Banks}

The impact of Alipay on commercial banks is mainly reflected in the following aspects:

(1)The flourishing development of Alipay has won a large number of customers favor, with a certain scale of customer base, these customers have operators on the platform. There are online shopping consumers, Alipay can pay in the field of third-party rapid and steady development, can not do without the credit of these customer groups, all business is based on a large number of active customers. And commercial banks do not necessarily have this high-quality condition even if business transformation does Internet finance.

(2)Has changed people's daily life style. Nowadays, the Internet has covered all aspects of people's life. Indeed, it has become an indispensable way of life. At the same time, network information technology has permeated every aspect of our life, intelligent. Personalized electronic products have become an important tool in our daily life and social entertainment. Based on this 
rapid evolution, the future customers to achieve the level of commercial banks have a higher demand for the status quo. People only need to use a variety of mobile terminals at home, they can solve many things on the Internet. In this social background, Alipay emerges as the times require, relying on its advantages. The quality of user experience, in the field of e-commerce occupies a place.

(3)In 2013, Alipay launched Yu'e Bao, which created a powerful "butterfly effect" in the Internet finance industry. Yu'e Bao from the point of view of pro-people strategy, the single amount of money into the very low limit, only need a single sum of money to realize the transfer, temporarily. Yu'e Bao harvested a large number of small users only half a year on the number of accounts registered more than 50 million, raised more than 10 billion yuan in only two months online. By contrast. The threshold of various financial management products launched by commercial banks is relatively high, which is more than 10,000 yuan. At the same time, the annual yield of Yu'e Bao is far higher than that of commercial banks and the banks have a "money shortage", which has caused huge industry pressure on our commercial banks in financial products.

\section{Measures Taken by Commercial Banks to Respond to Third-Party Payments}

\section{Improve Security System and User Experience}

The bank should strengthen the construction of the security supervision system of the commercial bank, extensively absorb the technical personnel of the network finance security at home and abroad, and jointly research and develop the safety supervision system to meet the needs of the modern development. Actively promote the combination of security system and user experience research. At the same time, learn from the successful case of third-party payment enterprises, change thinking, stand in the perspective of operating users. Deeply understand and consider the operational needs of customers, and actively optimize the various business functions of online banking.

\section{Strategic Cooperation with Third-Party Payment Enterprises to Actively Develop C2C Market}

In the current C2C market environment, both parties lack trust, and the two parties are mainly engaged in third - party secured transactions during the course of the transaction . It can effectively reduce operating costs and reduce the risk of capital. In cooperation with third-party payment enterprises, we can bring their advantages into full play, and realize complementary advantages and win-win cooperation. One is that third-party payment agencies can rely on banks, a powerful industry financial giant, to create a more human face.

\section{Optimize Payment Solutions to Ensure B2B B2C Market Dominance}

The bank should draw lessons from the successful experience of the third party payment enterprise, take its essence, make clear the development direction of the corresponding business, study the different commercial operation means among the industries, and refine and extend the function of the payment product. To maximize the advantages of products, at the same time in the face of different financial payment problems, to provide timely and effective payment solutions. Pay attention to the leading position of B2B B2C market. To strengthen the efficient operation of industry payment, to look at the financial payment market from the perspective of development, and to promote the sustainable development of commercial banks through continuous reference and learning.

\section{Keep Pace with the Times and Improve the Ability of Independent Innovation}

Banks can not just stay in the traditional business model, should actively integrate into the rapid development of financial payment environment, with the times, widely absorb domestic and foreign financial payment industry professionals. Actively create a professional and innovative financial atmosphere to achieve the perfect combination of bank advantage projects and the Internet, strengthen the talent team, and find out the current financial payment market situation and 
development law. And real-time feedback of relevant information can timely and effectively take appropriate countermeasures and measures to promote the development of banks and enhance the competitiveness of banks.

\section{Conclusions}

In the current Internet financial environment, on the one hand, the relationship between commercial banks and third-party payment institutions presents friendly cooperation, which gradually turns into a situation of intensifying competition, and commercial banks rely on their own good reputation. The advantages of business scope, on the basis of the original customer resources, on the basis of its online trading platform gradually achieve autonomy. On the other hand, third-party payment enterprises can effectively predict the financial market. From the perspective of development, with the rapid development of third-party payment business, the impact on commercial banks is inevitable and even intensified. In the face of this shock, quotient In order to compete with the third party payment on the basis of consolidating the original advantages, the bank also needs to provide the necessary services with the third party payment enterprise in a creative mode of cooperation.

\section{Acknowledgement}

This research was financially supported by the China Institute of Degree and Graduate Education Project "Accounting graduate student manual training course set" (2015Y0502)and Xi'an University of Science and Technology project "accounting manual training reform and innovation research" (ZX16066).

\section{References}

[1] Xue-Rong ZHENG. Study on the influence of Third-party payment on the Intermediate Business of listed Commercial Banks. [D] .Shanxi University of Finance and Economics.2017.

[2] Si-fan ZHANG . Research on the Impact of Third Party Payment on Commercial Banks and Countermeasures Research, D.D . Shanghai Normal University, 2017.

[3] Bing WANG . Study on the influence of the Development of Third-Party payment on Commercial Banks in China. [D] .Anhui University.2017.

[4] Wen-Yin QIN. The influence of Third-party payment on the profit of Commercial Banks in China. [D] .East China normal University.2016.

[5]Liu-Ni HE.Research on the influence of Third-party payment on Commercial Banks' earnings. [D] .South China Agricultural University.2016.

[6]Yu LUOResearch on the Development of Third-Party payment and its influence on Commercial Banks in China. [D] .Guangdong University of Finance and Economics.2015. 